\title{
La habitabilidad y la transdisciplinariedad
}

\author{
Mónica Espinosa Zurita
}

Invitada internacional

Universidad Nacional Autónoma de México, México

\section{Resumen:}

Este artículo aborda la habitabilidad, el espacio habitado y las acciones propias del habitante en una casa. Estos tres elementos interactúan de manera dinámica permanente en diferentes momentos de vida. El objetivo es hacer una reflexión sobre la habitabilidad, incorporando a la arquitectura elementos psicológicos, sociales, antropológicos para mejorar la vida y la salud del habitante de la ciudad. Se plantean aspectos perceptuales, sociales, institucionales y culturales que construyen identidades y fortalecen el ser personal y grupal, manifestándose en costumbres, ritos, narrativas, huellas de memorias, significantes, significados y en los objetos que los acompañan.

Palabras clave: arquitectura, discurso, espacio habitado, habitando, habitante, interacción.

\section{Habitability and transdisciplinarity}

\begin{abstract}
:
This paper approaches habitability, living space and a house dweller's own actions. These three elements interact dynamically and continually in life's different moments. The purpose is to reflect on space habitability adding to architectural concepts psychological, social and anthropological elements that could enhance quality of life and health for the city dweller. Several perceptual, social, institutional and cultural aspects that help build identity and strengthen the personal and group being that are expressed in uses, rites, narratives, memories, signifiers, meanings and their accompanying objects are explored.
\end{abstract}

Keywords: architecture, discourse, inhabitant, interaction, living space, living.

\section{Mónica Espinosa Zurita}

Arquitecta. Estudiante del Programa de Maestría y Doctorado en arquitectura, Facultad de Arquitectura, Universidad Nacional Autónoma de México. 


\section{Introducción}

L

a casa es un tema importante para el ser humano: debe satisfacer la necesidad de protección del exterior y debe albergarlo junto con sus objetos para que tenga un territorio privado e íntimo en donde desarrollar comportamientos propios de su cultura e idiosincrasia.

En las grandes ciudades el espacio es cada vez menor y más caro. La tendencia es a construir de manera vertical para albergar a mayor cantidad de personas en un área menor, con un gasto menor en instalaciones. La demanda de los espacios habitacionales se incrementa, así como su costo, existiendo un déficit en este renglón. El proyecto arquitectónico podría incorporar de manera transdisciplinaria otros elementos que enriquezcan el espacio habitado, brindando al habitante mejores maneras de estar en el lugar y que en consecuencia mejoren la calidad de vida.

Sabemos que el problema es complejo, ya que existen otros elementos que son ajenos al proyecto. Las tendencias constructivas, acompañadas del acelerado crecimiento demográfico, exigen mejorar los espacios en cuanto a la habitabilidad.

La habitabilidad es un sistema complejo por los elementos que le componen. Entre ellos podemos hablar de una triada inicial: El "habitante" que opera "habitando" el espacio, generando comportamientos e interactuando en el "espacio habitado". El fenómeno se nutre de aspectos sociológicos, antropológicos, psicológicos que van dando unos matices y quiebres que no pueden ser mirados de manera lineal desde una sola perspectiva. En este sentido queremos reflexionar sobre estos elementos que le acompañan y le son propios.

\section{La Habitabilidad y la Transdisciplina}

El hombre, desde que nace hasta que muere, habita. El espacio le aporta al hombre un sentido de orden a su mundo de acontecimientos y acciones, poniendo un territorio como espacio de propiedad.

Al interiorizar de manera inconsciente el lugar del habitar, sabemos por costumbre dónde queda el camino de nuestro recorrido cotidiano: el del café de la mañana, el del ritual del baño, el almuerzo, el vestirnos e irnos al trabajo. Historia de los intercambios pasados y el balance de esas transacciones en el momento, son también la historia de la negociación que ha conducido a esa unión y a los intercambios a los que ella ha dado lugar (Bourdieu, 2007).

Estas prácticas cotidianas estructuradas viven en lo actual, configuran un sistema complejo de actividades, percepciones y movimientos corporales que se dan en el habitus ${ }^{1}$ de manera subjetiva, mecánica, espontáneas, siendo fuerzas de pensamiento que se convierten en actos rituales inherentes a una condición del habitar. Producto de la historia, el hábitus que origina prácticas individuales y colectivas, y por ende historia, registradas en cada organismo bajo la forma de esquemas de percepción, de pensamientos y de acción, se extiende con más seguridad que todas las reglas formales y todas las normas explícitas (Bourdieu, 2007).

En la lógica específica de los organismos en los cuales están incorporadas de manera duradera, sistemática y no mecánicamente como sistema adquirido de esquemas generadores, el habitus hace posible la producción libre de todos los pensamientos, todas las percepciones y todas las acciones inscritas en los límites inherentes a las condiciones particulares de su producción (Bourdieu, 2007).

Según Lima (1992), las necesidades no son más que las disposiciones del habitus. Toda esta estructura define las necesidades y los límites de su satisfacción y simultáneamente las condiciones objetivas influyen sobre este sistema de predisposición. El habitus es

$1 \quad$ El habitus se diferencia del hábito en el sentido en que el habitus es un producto condicionado, se encarna en nuestra manera de ser bajo la forma de disposiciones permanentes es algo poderosamente generador, es adaptación. Bourdieu (1980). la base de toda elección "realista", en donde se excluye todo aquello que se considere inaccesible (Bourdieu, 2007).

Los sentidos son fundamentales para satisfacer las necesidades y encontrar un territorio y percibir al mundo. Con la evolución del hombre se desarrollaron los cuerpos 
sensoriales, los "receptores de distancia", la vista, el oído, el olfato y el tacto. La cultura, sin que se den cuenta, excluye cierto tipo de información, teniendo normas de percepción (Bourdieu, 2007).

Bien lo dice Rasmussen (2004), "rara vez somos conscientes de todo lo que podemos percibir; aunque tenemos una impresión inmediata de los objetos que estamos mirando, no pensamos en los distintos sentidos que han contribuido a crear esa impresión", es algo que sentimos, sea por los colores, la iluminación, los sonidos, las texturas, los olores, nuestros sentidos están inmersos en esa impresión.

El modo de percibir el espacio es importante. Se ha estudiado que cada grupo histórico ha formado su propio criterio de lo estético, llamado bello o no bello, agradable o desagradable, porque depende de sus tradiciones, sus rituales, sus recursos económicos, su sitio geográfico o su territorio, y se ha determinado que este percibir se va modificando con el tiempo histórico de cada región, y es dependiente de sexo, posición, y clase.

También la percepción del espacio está dada de acuerdo a las memorias de la infancia, a la oportunidad de los espacios y a la trayectoria de vida, encontrándose distorsionada por las emociones y los símbolos construidos en el contexto social. La sensación que el hombre tiene del espacio está relacionada muy de cerca con su sensación de sí mismo, vinculada con su medio (Hall, 2011).

En este sentido el espacio habitado es la mediación entre el cuerpo y el mundo; los espacios concretan y hacen visible un lazo entre la memoria familiar y la individual. La construcción en diferentes momentos de esta memoria permite al individuo reconocer, dar temporalidad y escenario a las emociones, produciendo internamente identidad, simbología y significado. La forma de tener acceso a este recorrido interno es de manera oral, las narraciones de las experiencias concretas de esa vida social y personal, son los lugares de la memoria: fiestas, reuniones familiares, conmemoraciones, es la forma en que los individuos dotan de sentido al espacio. El compartir el espacio y la vida cotidiana determina la pertenencia a un grupo (Pensado, 2004).

Al percibir los objetos la persona descubre los secretos de los signos y sus representaciones, conoce sus virtudes, su naturaleza, los construye intelectualmente por medio del pensamiento, entonces es la tarea del lenguaje dar símbolo y significado al conocimiento de los objetos; saca, por así decirlo, del interior del ser que lo percibe en un contexto, tomando certidumbre al identificarlo y al nombrarlo.

El signo es el que permite el análisis de otras operaciones complejas, formando sistema de signos que se entrelazas formando la construcción de cuadros que fijan las composiciones del espacio, del tiempo y de un lugar habitable junto con las actividades y objetos que se integran a este cuadro. La red compleja de signos se liga y articula según los cortes del propio sentido.

Entonces el habla representa el pensamiento, es el núcleo de la representación y contiene en ello la significación del objeto; el leguaje es la representación que tiene el poder de ordenar pues el discurso se encarga de marcar la época de los acontecimientos, de la simbología, más allá de la palabra misma, y da figuras, modos y circunstancias no expresadas, que le pertenecen al hablante de manera inconsciente, "lo dice entre líneas, sin decirlo", estableciendo identidades, diferencias, caracteres, expresando rasgos que le pertenecen al individuo y al grupo (Foucaut, 2009).

Las primeras costumbres se constituyen según los esquemas de la reacción circular, aparecen los comportamientos que preparan la inteligencia sensorio-motora, asimilando y acomodando los estímulos en términos de organización espacial, social y emocional. Luego se dará la bienvenida a la siguiente etapa del pensamiento y del lenguaje, donde el niño podrá nombrar los objetos, realizar imágenes mentales y representaciones simbólicas como los dibujos, teniendo así un ordenamiento mental de conjuntos y clasificación de los conceptos de causalidad, espacio, tiempo y velocidad (Piaget, 1920).

El lenguaje está ligado y entrelazado a un sistema conceptual del mundo generado por un sistema de producción que aterriza de manera específica en el trabajo y en la vida cotidiana, las palabras contiene valores que representan un modo de ser, una ideología indisoluble y propia (Bourdieu, 2001). 
En la vida cotidiana y la casa se representa una forma de conceptualizar al mundo, en dónde me ubico socialmente, en un sistema de objetos y símbolos cosificados, mas allá está la narrativa no verbal de deseos dignificados, formas, pensamientos, historias y memorias, con las que se conforma la realidad del concepto que tengo del mundo de manera inconsciente, por ello le pongo a los objetos significados y signos que representan en la vida cotidiana del habitante, dándole una identidad al ser que habita (Lefebvre, 1970).

La familia es la institución social que sugiere una forma de comportamiento para las relaciones colectivas dadas principalmente en la casa. Otorga funciones específicas de acuerdo al género, a la edad o posición en el gremio. En la institución familia existe una lógica de roles que se han desempeñado históricamente, controles que regulan los límites y el comportamiento de sus miembros, un status cognitivo dentro del mundo social, que da orden a la institución; "todos saben" sobre el mundo social, se interioriza como "verdad" objetiva validada en el curso de la socialización. El lenguaje se convierte en el depositario de sedimentos colectivos, los actores deben entender los significados para realizar las acciones institucionalizadas, lo que requiere un proceso "educativo" de los significados (Lefebvre, 1970).

Este proceso se aprende a través de los rituales que tienen como escenario necesario el hábitat. El ritual es la forma que tiene de actuar lo institucional. El ritual tiende a consagrar una forma de hacer las cosas, poniendo un "como" arbitrario; si bien su efecto es pasar desapercibido, actúa diferenciando, separando, para indicar este camino, teniendo al mismo tiempo un sentido simbólico.

De tal suerte que el ritual es un acto de magia de la propia institución social de la familia, y se manifiesta de diversas maneras en el género, en las actividades, en el tipo de autoridad. La institucionalización puede producirse en cualquier zona de comportamiento de las relaciones colectivas, afectando al individuo (Bourdieu, 2007). Le da "roles" que desempeñan controles, y estatus cognitivo que se va interiorizando en el desarrollo de la personalidad del individuo. La manera de expresarlo es comunicándolo para "identificarme con", lo que le da al individuo Identidad por "pertenecer a" y se expresa de manera pública; se crea en esta institución de lo familiar una frontera imaginaria. Se hereda con la costumbre cotidiana "un ritual" que se entreteje con el sentido de un límite, aunque sin palabras los actos dan esta visión del mundo particular del grupo, convirtiéndose en reglas no escritas que se manifiestan hacia afuera y hacia dentro (Bourdieu, 2007).

El lenguaje le da palabras al ritual, pudiendo nombrarlo con el sentido común, entonces el ritual es un orden institucional, es el comportamiento de lo que "debe hacerse" y va acompañado de significados y símbolos del grupo (Bourdieu, 2007).

En la vida cotidiana, estos símbolos emergen de los simples objetos que son confidentes psicológicos de los individuos, son la simple decoración que adquiere sustancia y perspectiva, encontrándose en la frontera absoluta entre el interno y el externo y conforman el modus vivendi.

Los objetos (muebles o objetos decorativos) son un continente fijo cuyo exterior es sustancia, y que aparte de su función práctica tienen una función primordial de recipiente de lo imaginario, de receptividad psicológica, y son el reflejo de una visión del mundo concebido como "recipiente de interioridad" y de las relaciones como correlaciones trascendentes de las sustancias; siendo la casa misma el equivalente del cuerpo humano (esquema orgánico), esquema que se generaliza como esquema ideal de integración de las estructuras sociales, es decir compone un modo total de vida, un orden de la naturaleza (Baudrillard, 1968).

La manera de conceptualizar el mundo se apoya en la familia; el individuo se siente enraizado con identidad como parte de "ellos". La familia proporciona los comportamientos que ordenan y prohíben, generando formas de arraigo, primero como sentido de territorio, localizado en un "lugar" domiciliado. Primero el niño está enraizado a su madre y al lugar que comparten, luego en su infancia histórica, generando salud mental, dándole sentido a su vida e identidad. Conformando así la idea de un tipo de MUNDO, formando sus creencias expresas como ritos y costumbres, ideologías que comprenden modos de ser y hacer en el mundo, formas para resolver las necesidades y que forman a la personalidad madura (Fromm, 1964). 
El territorio es la casa y la vida cotidiana, el lugar en donde nace el individuo, donde nace su intimidad, su concepción del mundo, donde se da arranque a la construcción de la personalidad, se forma en el ser del tiempo-espacio, donde comienza la construcción de los objetos, el lenguaje, la idiosincrasia, la identidad. Es en casa, con toda la complejidad que tiene el individuo y el grupo, con sus prácticas de valores, con sus prejuicios, con los criterios estéticos de su cultura histórica y tradicional, con los diferentes actores que realizan el marco multicolor de esta vida anónima, con sus diferentes edades, tiempos, con sus circunstancias personales, que la gente toma consigo las interiorizaciones del espacio y de caracteres aprendidos al principio de su vida.

Al describir narrativamente el lugar en que habitamos, podemos imaginar los objetos o lugares en un sistema de otras dimensiones. El sentido de orientación también es base del reconocimiento de nuestra posición en el espacio, por medio de puntos de referencia o particularmente de la forma de ese espacio. Con el sentido de orientación podemos identificar el arriba, el abajo y el alrededor, podemos reconocer las formas e interpretar los mensajes con ayuda del desplazamiento, de recorridos, y a través de éstos podemos adquirir la experiencia del espacio, a la vez que reconocer la existencia misma por los acontecimiento que el ocurren. Descubrimos el mundo por medio de recorridos y lo asumimos a partir de los mapas -como representación del espacio-que elaboramos en esos recorridos, y así como descubrimos el primer territorio que recorrimos más allá de nuestro propio cuerpo, el cuerpo de la madre con sus rincones de tibieza, alimento y amor, luego recorremos el cuerpo de la persona amada. En espacio tenemos experiencias sensibles y emocionales que le dan sentido a la vida, llevando a tener una significación, formando entonces imágenes simbólicas de los espacios habitados: teniendo tránsitos y demoras, formando en el inconsciente del sujeto una imagen propia del espacio, convirtiéndolo en escenarios que implican acciones significantes (Pérgolis y Moreno, 2010).

En su espacio, el hombre esta "subjetivamente centrado" como ombligo del mundo, así como lo entendían los antiguos griegos y los romanos (caput mundi) (Norberg-Schulz, 1975). El hombre, desde que nace, habita ${ }^{2}$ y se localiza en un lugar. Las preguntas ¿En dónde vives? ¿Cuál es tu dirección? encuentran significado cuando el ser que habita se identifica adscrito a un lugar. Va unido a un lugar edificado por el hombre llamado espacio habitable (casa, departamento, vivienda).

El espacio habitable es el objeto arquitectónico, donde se puede entrar, permanecer 0 salir. Es aquel que reúne objetos para darle uso a ese habitar y les da una significación a los objetos haciéndolos propios, más allá del uso mismo, acompaña a nuestras memorias de vida. El lugar es un espacio cerrado, que queda separado de los alrededores, como un lugar particular (Norberg-Schulz, 1999).

El espacio debería de ser "el hábitat"3 para el usuario, donde adquiera experiencias significativas, un sitio donde las actividades se ven engrandecidas y desarrolladas de acuerdo a convenciones culturales y sociales, que se reflejan no solo en forma y apariencia física (materiales, pintura, objetos arquitectónicos), sino en la configuración de cada uno de los elementos que integran el diseño, conteniendo identidad del lugar y del que lo habita.

El espacio comunica y refleja el contexto del habitante, expresa la esencia del ser, de su Yo y de su cosmovisión del mundo (Pérgolis y Moreno, 2010). El lugar sugiere formas de comportamiento, dando lugar a un "proceso de socialización" y de adaptación con sistemas de símbolos en los diferentes espacios. La socialización implica aprender a comportarnos de formas específicas ante cosas específicas: en otras palabras, qué

2 Habita, Habitado. Habitar. Del latín habitāre. Vivir, morar. El espacio habitado es la mediación entre el cuerpo y el mundo, los espacios concretan y visualizan un lazo entre la memoria familiar e individual.

$3 \quad$ Hábitat es el lugar que contiene las condiciones apropiadas para que viva un organismo, especie o comunidad animal o vegetal Se trata del espacio en el cual una población biológica puede residir y reproducirse, de manera que asegure su presencia perpetua en el planeta. fenómenos determinados se han relacionado con objetos determinados (NorbergSchulz, 1998). Los objetos pueden disponerse en sistemas que describan el mundo. Es conveniente dividir los que hay en nuestro ambiente en objetos "físicos", "sociales" y "culturales" (Norberg-Schulz, 1999).

Por lo que el quehacer de la arquitectura es escuchar a los seres que habitan y a su colectividad, para resolver y respetar esencialmente su voluntad e interpretar y proyectar objetos, así como construir espacios habitables, más allá de protegerlos del ambiente (frío, calor, viento, lluvia, sol...). En la casa el hombre encuentra su identidad, tal como señala Bachelard (2013) la casa es "una de las grandes fuerzas integrales de la vida del 
hombre. La casa del hombre es el lugar que tiene éste en la tierra". Habitamos y somos habitados. "...una casa sólo es tal cuando el hombre la habita, la vive colmándola con sus costumbres, sus anhelos, sus angustias, sus sueños” (González, 1999).

La casa donde crecimos y pasamos la infancia: en cada ladrillo, en cada hueco, en cada espacio, va entretejiendo las memorias de nuestra historia que se queda en el imaginario y toma significado en el inconsciente; esa casa, cuando la habitamos expresamos las connotaciones que nos evoca. Aún con el paso del tiempo, cuando dejamos de estar, sigue teniendo significado, es más que una casa vieja, es nuestra casa, la casa de nuestra infancia, donde se formo nuestro Yo y nuestra concepción del mundo. Al estar ahí en el imaginario, podemos evocar el olor de las plantas, el olor de la comida, el jardín, el perro ladrando, la mamá llamando para la comida; escuchamos las melodías de aquella época, la escenografía se muestra con muebles, colores y objetos variados, la algarabía de la compañía de los hermanos. Las calles y los espacios públicos, los personajes y actividades desarrolladas. Esta es la experiencia interiorizada del habitante del lugar llamado hogar. Le damos un significado colectivo por medio de un ritual, lo institucionalizamos, lo repetimos, creamos una historia, volviéndose iconos de nuestras memorias individuales y colectivas.

En este sentido el objetivo de la arquitectura es servir al hombre, permitiendo ofrecer un espacio que permita realizar actividades humanas relacionadas con las costumbres, tradiciones y modos de vida típicos del lugar en donde se encuentra.

En términos arquitectónicos la habitabilidad se ocupa del aislamiento térmico y acústico, y de la salubridad, dedicada a asegurar unas condiciones mínimas de salud y confort en los edificios. Protege al ser humano para que pueda defenderse del frío, del calor, de los vientos, de las lluvias, de las sequías, y de las enfermedades. Existen elementos físicos (iluminación, acústica e iluminación), elementos psicológicos (proxemia ${ }^{4}$, percepción ambiental, etc.).

El contexto del habitante, expresa la esencia del ser, de su Yo y su cosmovisión del mundo. El lugar sugiere formas de comportamiento, en las que existe un "proceso de socialización" y de adaptación con sistemas de símbolos en los diferentes espacios. La socialización implica que aprendemos a comportarnos de formas específicas ante cosas específicas: en otras palabras, que fenómenos determinados se han relacionado con objetos determinados (Norberg-Schulz, 1999). Los objetos pueden disponerse en sistemas que describan el mundo. Es conveniente dividir nuestro ambiente en objetos "físicos", "sociales" y "culturales" (Norberg-Schulz, 1999).

En términos arquitectónicos la habitabilidad se ocupa del aislamiento térmico y acústico y de la salubridad, dedicada a asegurar unas condiciones mínimas de salud y confort en los edificios. Protege al ser humano para que pueda defenderse del frío, del calor, de los vientos, de las lluvias, de las sequías, y de las enfermedades. Existen elementos físicos (iluminación, acústica e iluminación), elementos psicológicos (proxemia, percepción ambiental, etc.).

Los primeros requisitos de la habitabilidad son que la persona quepa junto con sus objetos y pueda satisfacer sus necesidades básicas:

Aislamiento Acústico. Protección contra el ruido para proteger a las personas evitando molestias físicas, emocionales y psicológicas.

Aislamiento térmico. Logrando un clima adecuado para que las personas se sientan a gusto, circulación del aire, humedad, orientación y dirección de las ventanas y el tipo de materiales para lograr el aislamiento térmico para obtener la temperatura adecuada.

$4 \quad$ Proxemia, proxémica, vienen del latín proximus (de prope, cerca) y ximus (más como el máximo). En 1963 el antropólogo Hall, E.T. estudio los efectos de la proximidad o acercamiento físico entre los seres humanos en sus relaciones (entre más cercanía emocional mayor intimidad, menor cercanía menor intimidad). (Edward T. Hall,2011). lbídem
Salubridad. En este apartado se encuentran iluminación natural (donde las personas permanecen) y artificial (en destinados para el aseo y en garajes), ventanas para que el lugar se ilumine, se ventile y que sirvan para mirar afuera y desde afuera sirvan para mirar adentro. El adecuado abastecimiento de agua potable, así como la correcta canalización, evacuación o desalojo de las aguas residuales.

Dimensiones mínimas dentro de las condiciones de habitabilidad. Existe un tamaño mínimo tanto para las viviendas como para sus distintas piezas (dormitorios, aseos, salón, etc.). Dimensiones de la persona, y los objetos para su movilidad y los objetos. 
El programa biológico de la vivienda requiere habitaciones para albergar a la familia compuesta por padre, madre, y dos hijos de distinto sexo, contendrá como mínimo tres dormitorios (Gónzalez, 2013). Sin embargo existe diversidad de variantes de ocupantes en un espacio habitado: Madres solteras con hijos, familia extensa, personas solteras etc. Por lo que aquí, solo se da un ejemplo de las lógicas de la producción de la arquitectura actual.

De acuerdo a Fonseca (1995) existen tres áreas importantes que debe contener una casa: Zona social, zona privada y zona de servicio. La casa debe tener paredes y techo. Las paredes dividirán las habitaciones aislándolas del ruido y dando al habitante privacidad. Estos dos elementos darán protección y aislamiento contra la naturaleza como lluvias, animal y otros seres humanos. Los espacios necesarios son:

Cocina. Espacio que contiene los instrumentos, herramientas y objetos para cocinar, una mesa para trabajar, una estufa para cocer, una tarja para lavar, espacio para almacenamiento frío (refrigerador), y para almacenamiento a temperatura ambiente (latería, semillas, utensilios).

Comedor. Un espacio en donde la familia se sienta a comer y socializar.

Baño para las necesidades de higiene, con regadera, escusado y lavabo para afeitarse, maquillarse etc.

La sala es el espacio de uso común, el lugar social para recibir visitas, Ahí convive y se integra la familia, suele tener mesas, sillones, sofá y la televisión. Un lugar para poner la computadora.

Recámara en este lugar se duerme y se descansa, ahí se tiene una proximidad más cercana; también es lugar para guardar, ropa, zapatos, artículos personales, documentos, etc. o televisión y juegos de entretenimiento.

Área de servicio. Lugar para lavar ropa, área de tendido, guardar artículos de limpieza y objetos que no se utilizan.

Con lo anterior podemos definir la vivienda como: "Lugar cerrado y cubierto, construido para ser habitado por personas"' La vivienda es un hecho intrínseco de la humanidad, es una necesidad ancestral, pero del mismo modo es un inminente hecho social, de ella depende en gran medida el desarrollo y bienestar de los habitantes de una población, es un referente del contexto social y económico que envuelve a una sociedad determinada.

Al no cumplirse las condiciones de vida, se habla de hacinamiento. De acuerdo a la Organización Mundial de la Salud (OMS) el hacinamiento ${ }^{5}$ se refiere a la respuesta psicológica de la gente a la densidad de población como medida objetiva del número de personas que viven por unidad de superficie. Al incrementarse la densidad se disminuye la calidad de vida. Efectos físicos: Propagación de enfermedades infecciosas, deterioro en las prácticas de higiene, incremento de la aglomeración, contacto físico. Efectos psicológicos: Frustración, ansiedad, angustia, estrés, fobias, depresión, deterioro de la salud mental. Efectos sociales: Violencia, alta morbilidad y mortalidad.

Los criterios para establecer una situación de hacinamiento varían según los diferentes países. Se considera de 2 a 4 personas por habitación que no sean pareja. El hacinamiento también se da a todo nivel: personas por cama, personas por pieza. Si el indicador de hacinamiento supera las 5 personas por dormitorio la dimensión espacial se cataloga en condiciones de deficiencia irrecuperable. Una vivienda sin dormitorios también adquiere una condición de deficiencia irrecuperable en la dimensión espacial. La condición de hacinamiento de la vivienda es válida para todas las personas, núcleos familiares y hogares de dicha vivienda.

La psicología ambiental analiza el hacinamiento y los efectos del medio ambiente ${ }^{6}$ en el comportamiento individual y del grupo, refiriéndose a la ubicación del lugar, la infraestructura, equipamientos, servicios de la vivienda (Halagan, 2014). La idea del hacinamiento depende de un juicio normativo acerca de los niveles apropiados de ocupación, densidad y privacidad. La normatividad es ambigua y limitada a metros cuadrados y valor de la vivienda, o a cierto tipo de infraestructura.

El hacimiento está relacionado con la salud física y mental de las personas. La salud mental abarca una amplia gama de actividades directa 0 indirectamente relacionadas

$5 \quad$ El hacinamiento es la cantidad de personas que habitan en una vivienda por encima de la capacidad de ésta.

$6 \quad$ Ambiente se puede definir como: "Todos los contextos en que el sujeto (por ejemplo, casas de vivienda, oficinas, escuelas, calles, etc.) se pueda desarrollar..." 
con el componente de bienestar mental incluido en la definición de salud que da la Organización Mundial de la Salud (OMS): «un estado de completo bienestar físico, mental y social, y no solamente la ausencia de afecciones o enfermedades». Está relacionada con la promoción del bienestar, la prevención de trastornos mentales y el tratamiento y rehabilitación de las personas afectadas por dichos trastornos (Organización de las Naciones Unidas - ONU, 2000).

La salud mental se define como "un estado de bienestar en el cual el individuo es consciente de sus propias capacidades, puede afrontar las tensiones normales de la vida, puede trabajar de forma productiva y fructífera y es capaz de hacer una contribución a su comunidad".

La salud es un derecho humano fundamental que se define como "un estado de completo bienestar físico, mental y social, y no solamente la ausencia de enfermedad (ONU, 2000).

Ese estado de bienestar se ve alterado cuando la persona carece de vivienda que proporcione calidad de vida con los servicios fundamentales en materia de salud, seguridad, comodidad y alimentación (Maslow, 1991). El acceso a una vivienda adecuada puede ser la condición previa para el disfrute de varios derechos humanos, en particular en la esfera del trabajo, la salud, la seguridad social, el voto, la privacidad y la educación (ONU, 2000). En la Declaración del Milenio se señaló, "LA VIVIENDA" como determinante de la salud en América Latina y el Caribe y se enfatizó la relación entre la vivienda y la salud. Se expresó que las condiciones de la vivienda pueden promover o limitar la salud física, mental y social de sus residentes.

\section{Conclusiones}

El espacio habitable, la habitabilidad y el habitante son inseparables. Desde que nacemos hasta la muerte, siempre existe un escenario que nos acompaña. Al nacer, nos ubicamos en el mundo, aprendemos y asimilamos una idea del mundo habitándolo con sus formatos, sus distribuciones y los comportamientos que se generaran en ellos. Es necesaria analizar esta tríada con la complejidad y diversidad que contiene para proyectar y proponer espacios diversos para diferentes sectores y regiones.

Es clara la dinámica de la concentración en las ciudades, la globalización y las tendencias constructivas internacionales nos atrapan, formando rutas únicas que marcan pautas. Los grupos inmobiliarios junto con las alianzas del Gobierno delimitan la manera de generar vivienda y muestran una manera de habitar, reproduciendo el modelo en diferentes regiones, sin importar clima, estilo de vida, cultura o idiosincrasia.

Los aspectos culturales, sociales, económicos e idiosincráticos dan un tono para diferenciar lo habitable, en términos de su ocupación y de las dinámicas de comportamiento que ahí se generan, produciendo malestar o bienestar para el habitante, dependiendo de los accidentes o bondades del inmueble.

Es necesario ampliar el análisis de esta tríada de manera transdisciplinaria para trabajarla aportando a los proyectos formas más amigables de estar cercanos al entendimiento del habitante.

Estos tres elementos se conforman de manera compleja, no existe soluciones absolutas, solo aproximaciones que nos ayudan a comprender mejor la habitabilidad y los fenómenos que ahí se dan. 


\section{Referencias bibliográficas}

Bachelard, G. (2013). La Poética Del Espacio. México: Editorial Fondo de Cultura Económica (FCE).

Baudrillard, J. (1968). El Sistema de los Objetos. París: Siglo XXI.

Bourdieu, P. (2007). El Sentido Práctico. Buenos Aires: Siglo XXI.

Bourdieu, P. (2001). ¿Qué significa el habla? Madrid: Akal.

Fonseca, X.(1995). Las medidas de una casa: Antropometría de la Vivienda. México: Editorial Pax.

Fromm, E. (1964). Psicoanálisis de la sociedad contemporánea. México: FCE.

Foucault, M. (2009). Las palabras y las cosas: una arqueología de las ciencias humanas. México: Siglo XXI.

González, C. (1999). Vivienda y ciudad posibles. México: Editorial Escala. Universidad Autónoma De México (UNAM).

González, C. (2013). Hacia una teoría del proyecto arquitectónico. Cd. Juárez: Universidad Autónoma De Cd. Juárez.

Halagan, C. (2014). Psicología Ambiental: un enfoque general. México: Limusa Noriega Editores.

Hall, E. (2011). La Dimensión Oculta. México: Editorial XXI.

Lefebvre, H. (1970). La producción del espacio. Revista de Sociología (3).

Lima, F. (1992). Familia popular, sus prácticas y la conformación de una cultura. México: Instituto Nacional de Antropología e Historia (INAH).

Norberg-Schulz, C. (1998). Intenciones en Arquitectura. Barcelona: Editorial G.G.

Norberg-Schulz, C. (1975). Existencia, espacio y arquitectura. Barcelona: Editorial Blume.

Norberg-Schulz, C. (1999). Genius Loci. Hacia una fenomenología de la arquitectura. Xochimilco: División de Ciencias y Artes para el Diseño. Departamento de métodos y sistemas. UAM.

Maslow, A. 1991). Motivación y personalidad. Madrid: Díaz De Santos.

ONU-Hábitat (2000) Declaración del milenio (A/RES/55/2). Recuperado del sitio web: www.un.org/spanish/milenio/ares552.pdf

Pensado, P. (2004). El espacio generador de identidades: Análisis de dos comunidades: San Pedro de Los Pinos y El Ocotito. Historia Oral. México: Instituto Mora.

Pérgolis J.C. y Moreno, D. (2010). La capacidad comunicante del espacio. Bogotá: Universidad Católica de Colombia, Facultad de Arquitectura.

Piaget J. (1920). Psicología del Niño. Madrid: Ed. Morata, S. L.

Piaget J.(1975). Representación del mundo en el niño. Madrid: Ed. Morata, S.L.

Rasmussen, S.E.(2004), La experiencia de la arquitectura. Barcelona: Editorial Reverté.

Roa, A. (2002). La arquitectura como experiencia. Espacio, cuerpo y sensibilidad. Bogotá: Villegas/Universidad Nacional de Colombia.

Zevi, B. (1971). Saber ver la Arquitectura. Barcelona: Editorial Poseidón. 